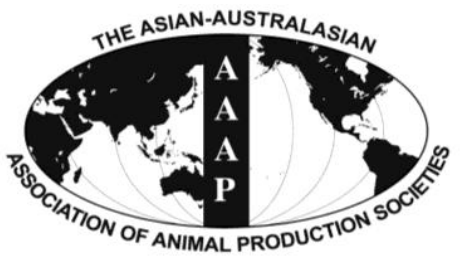

Asian-Aust. J. Anim. Sci.

Vol. 26, No. 1 : 116-121 January 2013

http://dx.doi.org/10.5713/ajas.2012.12414

www.ajas.info

pISSN 1011-2367 elSSN 1976-5517

\title{
Oligosaccharides Affect Performance and Gut Development of Broiler Chickens
}

\author{
Z. Ao ${ }^{1,2, *}$ and M. Choct $^{1}$ \\ ${ }^{1}$ School of Rural and Environmental Science, University of New England, Armidale, NSW, 2351, Australia
}

\begin{abstract}
The effects of oligosaccharide supplementation on the growth performance, flock uniformity and GIT development of broiler chickens were investigated. Four diets, one negative control, one positive control supplemented with zinc-bacitracin, and two test diets supplemented with mannoligosaccharide (MOS) and fructooligosaccharide (FOS), were used for the experiment. Birds given MOS or FOS had improved body weight (BW) and feed efficiency (FCR), compared to those fed the negative control diet during the 35-d trial period. The effect on FCR became less apparent when the birds got older. FOS and MOS supplementation reduced the pancreas weight as a percentage of BW, with an effect similar to that of the antibiotic, at $35 \mathrm{~d}$ of age. Birds given MOS tended to have a heavier bursa (p $=0.164)$ and lower spleen/bursa weight ratio $(\mathrm{p}=0.102)$ at $35 \mathrm{~d}$ of age. MOS and Zn-bacitracin showed a clear improvement on flock uniformity, compared to FOS. The mortality rate was not affected by FOS or MOS. (Key Words: Broiler, Oligosaccharides, Bird Performance, Organ Weight)
\end{abstract}

\section{INTRODUCTION}

The gut microflora directly affects the health status of the host animal (Brown, 1996; Lu et al., 2003; Klasing, 2007). Specific bacterial strains are thought to prevent colonization of the gut by pathogens and to improve the immune system of animals. A stable gut microflora helps the animal to resist infections, particularly in the gastrointestinal tract (GIT). This phenomenon has been described as competitive exclusion (Lloyd et al., 1977). Data in the literature indicate that the gut microflora can affect the immune status of the bird through its influence on the intestinal wall (Klasing, 2007).

Apart from its major roles in nutrient digestion and absorption, the gut is also the largest organ associated with immunity. It is thought to harbor over 600 species of microorganisms, which often affect its morphology and function (Apajalahti et al., 2004). It is assumed that the presence of stressors, such as toxins produced by micro-organisms, in the intestinal tract leads to changes in intestinal morphology such as shorter villi and deeper crypts, which will result in

* Corresponding Author: Z. Ao. Tel: +86-139-1075-3405, Fax: +86-10-6166-6991, E-mail: zao@alltech.com

${ }^{2}$ Alltech East Asia, 8 Guanghua Dongli, Jianguomenwai Avenue, Beijing 100020 China.

Submitted Aug. 2, 2012; Accepted Oct. 2, 2012; Revised Oct. 18, 2012 reduced absorption of nutrients and increased requirements for maintenance of the digestive tract.

In this study, the effects of mannooligosaccharides (MOS) and fructooligosaccharides (FOS) on GIT characteristics, including gut morphology, were investigated, compared with an antibiotic, Zn-bacitracin. The birds were exposed to a mild environmental challenge from day one by spreading old chicken manure on the floor of the cages.

\section{MATERIALS AND METHODS}

Four dietary treatments consisted of a negative control (basal), a positive control (Zn-bacitracin), MOS (BioMOS $^{\circledR}$, Alltech Inc., USA) and FOS (Raftilose $95^{\circledR}$, Orafti, Belgium). The two oligosaccharide products were added at a rate of $1.0 \mathrm{~kg}$ per tonne in the starter diet and $0.5 \mathrm{~kg}$ per tonne in the grower/finisher diet. Zn-bacitracin was added at the recommended level $(50 \mathrm{mg} / \mathrm{kg})$ to the positive control diet. Monensin was included in all four diets as a coccidiostat. The birds were fed a cold-pelleted sorghumsoybean meal (SBM) starter diet to $21 \mathrm{~d}$ of age and then a cold- pelleted sorghum-SBM grower/finisher diet, with or without the additives from $22 \mathrm{~d}$ until the end of the experiment at d 35 (Table 1).

One hundred and ninety-two (192), day-old male broiler chicks (Cobb) were placed in brooders and allocated to four replicates of 12 birds per treatment. At the end of the second 
Table 1. Broiler starter and grower diet composition

\begin{tabular}{lcc}
\hline Ingredients (\%) & Starter & Grower \\
\hline Sorghum & 66.0 & 73.7 \\
Soybean meal 48\% & 22.0 & 14.0 \\
Meat-bone meal 50\% & 8.5 & 8.0 \\
Vegetable oil & 1.6 & 2.0 \\
Limestone & 0.35 & 0.35 \\
Salt & 0.12 & 0.1 \\
Lysine-HCl & 0.35 & 0.44 \\
DL-methionine & 0.27 & 0.24 \\
L-threonine & 0.09 & 0.08 \\
Sodium bicarbonate & 0.24 & 0.15 \\
TiO 2 marker & 0 & 0.5 \\
Vitamin/mineral premix & 0.25 & 0.25 \\
Nutrients (calculated) & & \\
Crude protein (\%) & 23.0 & 19.8 \\
ME (MJ/kg) & 12.32 & 12.65 \\
Methionine+cystine (\%) & 0.89 & 0.76 \\
Lysine (\%) & 1.31 & 1.14 \\
Calcium (\%) & 0.92 & 0.85 \\
Available P (\%) & 0.48 & 0.45 \\
\hline
\end{tabular}

week, all the birds were transferred into AME cages. Birds from one brooder cage were randomly allocated into two cages to give a total of six birds per cage. All the birds were fed ad libitum throughout the experiment. The birds were housed in light- and temperature-controlled rooms. Continuous lighting was provided for the first three days, and then a $20 \mathrm{~h}$ daily lighting schedule was imposed until the end of the experiment. The room temperature was initially set at $34^{\circ} \mathrm{C}$ and gradually reduced to $22^{\circ} \mathrm{C}$ at $\mathrm{d} 21$. Old chicken manure was spread on the floor of the brooder and ME cages from day one to the end of the experiment in order expose the chickens to a mild environmental challenge.

The experiment was approved by the Animal Ethics Committee of the University of New England (Approval No. AEC01/090).

BW and feed intake on a per cage basis were recorded weekly for calculation of the weight gain and feed conversion ratio (FCR $=$ feed intake/weight gain) during the entire experimental period. Mortality was recorded daily. To calculate uniformity, birds were weighed individually at 35 days of age and the flock uniformity was determined by calculation of the $\mathrm{CV}$ of $\mathrm{BW}$.

On d 21 and 35, two chickens per cage were weighed and killed by cervical dislocation, and the small intestine, liver and pancreas were excised and weighed. The small intestine was divided into three segments: duodenum (from ventriculus to pancreo-biliary ducts), jejunum (from entry of the bile ducts to Meckel's diverticulum), and ileum (from Meckel's diverticulum to ileo-caecal junction). The length of the segments of small intestine was measured. Segments were flushed with cold deionized water, and the weight of empty segments was recorded. Weights of proventriculus and gizzard were recorded after the gut contents were removed. Pancreas and liver were removed and weighed. The weights were standardized by dividing by the BW to obtain the weight as a percentage of BW. At the same time, bursa of Fabricius and spleen were removed and weighed. The weights were expressed as a percentage of BW. Both intestinal weight and $\mathrm{pH}$ measurements were performed immediately following cervical dislocation. The ceca were weighed with their contents.

The $\mathrm{pH}$ of cecal and ileal contents was determined by modifying the procedure described by Corrier et al. (1990). One gram of intestinal content was diluted in $9 \mathrm{ml}$ of cold distilled water. The suspension was thoroughly mixed using a magnetic stirrer and the $\mathrm{pH}$ was determined by insertion of a glass electrode (EcoScan 5/6 pH meter, Eutech Instruments Pte Ltd., Singapore).

The levels of VFA in ileal and cecal digesta were determined by gas chromatography using the method described by Kocher (2000). For caecal VFA determination, $3 \mathrm{~g}$ of fresh digesta were diluted with $3 \mathrm{ml}$ of $0.1 \mathrm{M} \mathrm{H}_{2} \mathrm{SO}_{4}$ and thoroughly mixed. The sample was centrifuged $(12,000$ $\mathrm{g}, 15 \mathrm{~min}$ ). To an aliquot of $1 \mathrm{ml}$ supernatant, $0.1 \mathrm{ml}$ of a reference VFA (caproic acid) was added. The volatile acids were distilled using Thundberg tubes. The concentration of VFA was quantified using a Hewlett Packard 427 GLC.

To determine ileal VFA concentrations, the digesta sample was centrifuged $(12,000 \mathrm{~g}, 15 \mathrm{~min})$. To an aliquot of $1.3 \mathrm{ml}$ supernatant, $0.1 \mathrm{ml}$ of reference volatile fatty acid (caproic acid) and $0.1 \mathrm{ml}$ of $0.5 \mathrm{M} \mathrm{H}_{2} \mathrm{SO}_{4}$ were added. The volatile acids were distilled using Thunderg tubes. The sample was treated with two drops of $10 \mathrm{M} \mathrm{NaOH}$ and concentrated to dryness in a vacuum desiccator. The VFA salts were dissolved in $0.2 \mathrm{ml}$ of $0.5 \mathrm{M} \mathrm{H}_{2} \mathrm{SO}_{4}$ and were quantified using a Hewlett Packard 427 GLC.

To assess gut morphology, $2 \mathrm{~cm}$ segments from the jejunum ( $2 \mathrm{~cm}$ distal to the point of entry of the bile ducts) and the ileum ( $2 \mathrm{~cm}$ proximal to the ileo-caecal junction) were removed on sampling days for morphometric analyses. The intestinal samples were flushed clean with phosphate buffer solution (PBS) and fixed in 10\% neutral buffered formalin solution for at least $24 \mathrm{~h}$. The fixed tissue samples were processed in an automatic tissue processor (TOSCO, Thomas Optical \& Scientific Co., Melbourne \& Sydney, Australia) and embedded in paraffin using a Histo Embedding Centre (Leica EG 1160, Leica Microsystems, Bensheim, D-64625, Germany). Embedded samples were subsequently sectioned sagittally with a Rotary Microtome (Leitz 1516, Leica Microsystems, Bensheim, D-64625, Germany) at $5 \mu \mathrm{m}$. The tissue sections on the slides were 
stained using Harris's haematoxylin and eosin stains (Sigma, USA) and mounted with DPX Mountant for histology (Aldrich Chemical Company, Inc., Milwaukee, WI 53255, USA).

Morphometric indices were determined using computeraided light microscope image analyses (SPOT 3.1, Diagnostic Instruments, Inc., Sterling Heights, MI 48314, USA) as described by Bird et al. (1994). The morphometric variables analyzed included: villus length (from the tip of the villus to muscularis mucosa), villus height using the lamina propria as the base (from the tip of the villus to the villus crypt junction), villus width at half height, crypt depth as the depth of the invagination between adjacent villi, and thickness of the muscularis (the external muscle layer) and muscularis mucosa. Villus area was calculated from the villus height and width at half height. Values are means from 12 different villi and only vertically oriented villi and crypts were measured (Uni et al., 1999).

To determine the relative weights of lymphoid organs and level of immune responses, the bursa of Fabricius and spleen were removed and weighed on sampling days. The weights were expressed as a percentage of BW. Sheep Red Blood Cell (SRBC), a T-cell-dependent antigen, was used to measure the immune responses of the birds. Sheep blood was centrifuged at 2,000 $\mathrm{g}$ immediately after collection to harvest the red blood cells, which were then washed three times and diluted to a $5 \% \mathrm{vol} / \mathrm{vol}$ solution in $0.9 \% \mathrm{NaCl}$. At $21 \mathrm{~d}$ of age, eight birds from each treatment group were injected intraperitoneally with $1 \mathrm{ml} 5 \%$ SRBC solution. Blood samples were taken from the immunized birds seven days post-injection. The blood samples were kept at $4{ }^{\circ} \mathrm{C}$ for $24 \mathrm{~h}$ and then centrifuged at 2,000 $\mathrm{g}$ to harvest the sera. The sera were stored at $-20^{\circ} \mathrm{C}$ prior to analysis. Total antibody titers were determined by the method described by van Der Zijpp and Leenstra (1980), using the microtiter technique. Packed sheep red blood cells from the same sheep were resuspended into $0.9 \% \mathrm{NaCl}$ to make a $1 \%$ SRBC solution. Titers were expressed as the $\log _{2}$ of the reciprocal of the highest dilution giving complete agglutination. A half point was added if the next higher dilution showed partial agglutination.
All data were analyzed using Statgraphics software (Manugistics, Inc., 2000). ANOVA (by the general linear model procedure) was used to determine the significance of the main effects and interactions. Duncan's multiple-range test was used to separate means when significant effects $(p<0.05)$ were detected by multifactorial analyses of variance (Duncan, 1955).

\section{RESULTS}

Performance results are shown in Table 2. MOS, FOS and Zn-bacitracin significantly improved BW at both $\mathrm{d} 21$ $(\mathrm{p}<0.001)$ and $d 35(\mathrm{p}<0.05)$, compared with the negative control. Birds given MOS and FOS had improved feed conversion ratio $(F C R)$ at $\mathrm{d} 21(\mathrm{p}<0.05)$. This effect on FCR became less apparent as the birds got older, but still maintained a numerical difference. Birds with MOS and Zn-bacitracin supplementation had significantly lower CV of BW at $35 \mathrm{~d}$ of age $(\mathrm{p}<0.01)$, showing a positive effect on flock uniformity. FOS supplementation showed no effect on flock uniformity. The mortality rate of birds was not affected by dietary supplements.

Dietary supplementation of MOS, FOS and Znbacitracin had no effect on relative weights of bursa and spleen sampled on d 21 or 35. But FOS and MOS supplementation reduced the pancreas weight as a percentage of BW, with an effect similar to that of the antibiotic, at $35 \mathrm{~d}$ of age $(\mathrm{p}=0.025)$. Birds given MOS showed numerically heavier bursa $(\mathrm{p}=0.164)$ and numerically lower spleen/bursa weight ratio $(p=0.102)$ at 35 d of age (Table 3).

MOS supplementation tended $(\mathrm{p}=0.1)$ to increase cecal propionic acid level, but not the total VFA level (Table 4). The cecal $\mathrm{pH}$ and relative cecal weight were not affected by dietary supplementation.

MOS, FOS and Zn-bacitracin all increased the thickness of jejunal sub-mucosa $(\mathrm{p}<0.001)$ and reduced ileal villus height $(\mathrm{p}<0.001)$ at $\mathrm{d} 21$ (Table 5). In addition, Znbacitracin increased jejunal villus height and villus height/crypt depth ratio at $\mathrm{d} 21$. There was no effect of any treatment on crypt depth of the jejunum and ileum, and

Table 2. Effects of oligosaccharides and antibiotic supplementation on BW gain, feed efficiency and flock uniformity at 21 and $35 \mathrm{~d}$ of age $(\mathrm{n}=12)$

\begin{tabular}{|c|c|c|c|c|c|}
\hline \multirow{2}{*}{ Diet } & \multicolumn{2}{|c|}{ D 1 to 21} & \multicolumn{3}{|c|}{ D 1 to 35} \\
\hline & BW (kg) & FCR & $\mathrm{BW}(\mathrm{kg})$ & FCR & CV BW (\%) \\
\hline Control & $0.72^{\mathrm{b}}$ & $1.53^{\mathrm{a}}$ & $1.70^{\mathrm{b}}$ & 1.65 & $11.2^{\mathrm{a}}$ \\
\hline MOS & $0.81^{\mathrm{a}}$ & $1.46^{\mathrm{b}}$ & $1.84^{\mathrm{a}}$ & 1.60 & $8.1^{\mathrm{b}}$ \\
\hline FOS & $0.82^{\mathrm{a}}$ & $1.43^{\mathrm{b}}$ & $1.88^{\mathrm{a}}$ & 1.60 & $11.4^{\mathrm{a}}$ \\
\hline Zn-bacitracin & $0.81^{\mathrm{a}}$ & $1.48^{\mathrm{ab}}$ & $1.84^{\mathrm{a}}$ & 1.62 & $8.2^{\mathrm{b}}$ \\
\hline Pooled SEM & 0.016 & 0.022 & 0.046 & 0.034 & 0.99 \\
\hline $\mathrm{p}$ value (diet) & 0.001 & 0.020 & 0.030 & 0.700 & 0.010 \\
\hline
\end{tabular}

${ }_{\mathrm{a}, \mathrm{b}}$ Means within a column with different superscripts are significantly different $(\mathrm{p}<0.05)$. 
Table 3. Effects of oligosaccharides and antibiotics supplementation on gastrointestinal tract (GIT) and immune organ development at $35 \mathrm{~d}$ of age

\begin{tabular}{|c|c|c|c|c|c|}
\hline \multirow{2}{*}{ Treatment } & \multicolumn{2}{|c|}{ GIT (g/100 g BW) } & \multicolumn{3}{|c|}{ Immune organ (g/100 g BW) } \\
\hline & Intestine & Pancreas & Bursa & Spleen & Spleen/bursa $(\mathrm{g} / \mathrm{g})$ \\
\hline Control & $4.375^{\mathrm{a}}$ & $0.541^{\mathrm{a}}$ & 0.219 & 0.129 & $0.599^{\mathrm{ab}}$ \\
\hline MOS & $4.085^{\mathrm{a}}$ & $0.487^{\mathrm{ab}}$ & 0.237 & 0.119 & $0.496^{\mathrm{b}}$ \\
\hline FOS & $4.067^{\mathrm{a}}$ & $0.448^{\mathrm{b}}$ & 0.201 & 0.126 & $0.659^{\mathrm{a}}$ \\
\hline Antibiotic & $2.918^{\mathrm{b}}$ & $0.449^{\mathrm{b}}$ & 0.182 & 0.118 & $0.672^{\mathrm{a}}$ \\
\hline Pooled SEM & 0.183 & 0.021 & 0.013 & 0.007 & 0.044 \\
\hline Probability & 0.007 & 0.025 & 0.164 & 0.464 & 0.102 \\
\hline
\end{tabular}

${ }_{\mathrm{a}, \mathrm{b}}$ Means within columns with different superscripts are significantly different $(\mathrm{p}<0.05)$.

Table 4. Effects of oligosaccharides and antibiotic supplementation cecal VFA content $\mathrm{pH}$ and weight at d 35 ( $\mathrm{n}=8$ )

\begin{tabular}{|c|c|c|c|c|c|c|}
\hline \multirow{2}{*}{ Diet } & \multicolumn{4}{|c|}{ Cecal VFA content $(\mu \mathrm{M} / \mathrm{ml})$} & \multirow{2}{*}{$\mathrm{pH}$} & \multirow{2}{*}{$\mathrm{Ceca} / \mathrm{BW}(\%)$} \\
\hline & Acetic acid & Propionic acid & Butyric acid & Total VFA & & \\
\hline Control & 32.9 & 1.87 & 6.68 & 41.5 & 6.9 & 0.68 \\
\hline MOS & 32.1 & 2.33 & 5.69 & 40.2 & 7.3 & 0.54 \\
\hline FOS & 30.2 & 2.27 & 4.42 & 36.9 & 7.1 & 0.60 \\
\hline Zn-bacitracin & 33.1 & 1.55 & 6.19 & 40.8 & 6.9 & 0.54 \\
\hline Pooled SEM & 2.53 & 0.250 & 0.976 & 3.28 & 0.16 & 0.051 \\
\hline $\mathrm{p}$ value (diet) & 0.828 & 0.120 & 0.408 & 0.761 & 0.301 & 0.205 \\
\hline
\end{tabular}

Means within columns with different superscripts are significantly different $(\mathrm{p}<0.05)$.

villus height/crypt depth ratio of the ileum at $\mathrm{d} 21$. The day 28 data are shown in Table 6. FOS decreased $(p<0.01)$ the villus height of the jejunum and the ileum at $\mathrm{d} 28$, whereas Zn-bacitracin reduced $(\mathrm{p}<0.001)$ ileal villus height at $\mathrm{d} 28$. All three supplements tended $(\mathrm{p}=0.07)$ to reduce the thickness of jejunal crypts, while $\mathrm{Zn}$-bacitracin reduced $(p<0.05)$ the thickness of the ileal crypts $d 28$. There was no effect of any treatment on the villus height to crypt depth ratio both in the jejunum and the ileum on $\mathrm{d} 28$.

\section{DISCUSSION}

FOS supplementation has been reported to improve feed efficiency, weight gain, carcass weight and breast yield, and to reduce percentage of fat pad of broiler chickens (Ammerman et al., 1988; 1989). In addition, at $0.5 \%$ of inclusion, FOS was also able to reduce mortality. MOS supplementation of broiler diets has been reported to improve BW and FCR by $17 \%$ and $4.4 \%$ at $21 \mathrm{~d}$ of age $(\mathrm{p}<0.05)$, and $11 \%, 3.5 \%$ at $42 \mathrm{~d}$ of age, respectively (Kumprecht et al., 1997). Sims et al. (1999), who compared MOS with Zn-bacitracin, demonstrated that MOS and Znbacitracin improved the BW of broilers by 4.8 and $7.9 \%$, FCR by 9.1 and $9.9 \%$, respectively, at $42 \mathrm{~d}$ of age. The authors concluded that MOS was equivalent to $\mathrm{Zn}$ bacitracin in terms of performance improvement and financial return.

In the current study, birds given MOS or FOS had improved BW and feed efficiency, compared to those fed the control diet during the $35 \mathrm{~d}$ trial period. This effect on FCR became less apparent when the birds got older, which suggested that the effects of oligosaccharide supplementation on growth performance were more pronounced during the starter phase than the grower phase. In this study, flock uniformity was improved by MOS and Zn-bacitracin.

Table 5. Effects of oligosaccharides and antibiotic supplementation on histological development of jejunum ileum at $21 \mathrm{~d}$ of age $(\mathrm{n}=12)$

\begin{tabular}{|c|c|c|c|c|c|c|c|c|}
\hline & \multicolumn{4}{|c|}{ Jejunum } & \multicolumn{4}{|c|}{ Ileum } \\
\hline & $\begin{array}{c}\text { Submucosa } \\
(\mu \mathrm{m})\end{array}$ & $\begin{array}{l}\text { Villus height } \\
(\mu \mathrm{m})\end{array}$ & $\begin{array}{c}\text { Crypt depth } \\
(\mu \mathrm{m})\end{array}$ & 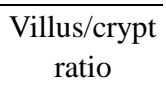 & $\begin{array}{c}\text { Submucosa } \\
(\mu \mathrm{m})\end{array}$ & $\begin{array}{l}\text { Villus height } \\
(\mu \mathrm{m})\end{array}$ & $\begin{array}{l}\text { Crypt depth } \\
(\mu \mathrm{m})\end{array}$ & $\begin{array}{l}\text { Villus/crypt } \\
\text { ratio }\end{array}$ \\
\hline Control & $18.0^{\mathrm{b}}$ & $865.9^{b}$ & 165.9 & $5.41^{\mathrm{b}}$ & 34.8 & $719.8^{\mathrm{a}}$ & 168.5 & 4.49 \\
\hline MOS & $28.1^{\mathrm{a}}$ & $876.8^{\mathrm{b}}$ & 163.0 & $5.51^{\mathrm{b}}$ & 30.0 & $598.6^{\mathrm{b}}$ & 145.5 & 4.33 \\
\hline FOS & $23.8^{\mathrm{a}}$ & $846.7^{\mathrm{b}}$ & 165.0 & $5.18^{\mathrm{b}}$ & 30.3 & $598.2^{\mathrm{b}}$ & 159.3 & 3.90 \\
\hline Zn-bacitracin & $25.4^{\mathrm{a}}$ & $989.3^{\mathrm{a}}$ & 146.4 & $7.01^{\mathrm{a}}$ & 30.4 & $548.6^{\mathrm{b}}$ & 143.8 & 3.88 \\
\hline Pooled SE & 1.6 & 32.9 & 10.1 & 0.31 & 1.6 & 17.7 & 9.5 & 0.28 \\
\hline $\mathrm{P}$ value (diet) & 0.001 & 0.010 & 0.400 & 0.001 & 0.100 & 0.001 & 0.200 & 0.300 \\
\hline
\end{tabular}

\footnotetext{
$\overline{\mathrm{a}, \mathrm{b}}$ Means within columns with different superscripts are significantly different $(\mathrm{p}<0.05)$.
} 
Table 6. Effects of oligosaccharides and antibiotic supplementation on histological development of jejunum ileum at $28 \mathrm{~d}$ of age $(\mathrm{n}=12)$

\begin{tabular}{|c|c|c|c|c|c|c|c|c|}
\hline & \multicolumn{4}{|c|}{ Jejunum } & \multicolumn{4}{|c|}{ Ileum } \\
\hline & $\begin{array}{l}\text { Submucosa } \\
\qquad(\mu \mathrm{m})\end{array}$ & $\begin{array}{l}\text { Villus height } \\
\quad(\mu \mathrm{m})\end{array}$ & $\begin{array}{l}\text { Crypt depth } \\
(\mu \mathrm{m})\end{array}$ & $\begin{array}{l}\text { Villus/crypt } \\
\text { ratio }\end{array}$ & $\begin{array}{l}\text { Submucosa } \\
\qquad(\mu \mathrm{m})\end{array}$ & $\begin{array}{l}\text { Villus height } \\
\qquad(\mu \mathrm{m})\end{array}$ & $\begin{array}{l}\text { Crypt depth } \\
(\mu \mathrm{m})\end{array}$ & $\begin{array}{l}\text { Villus/crypt } \\
\text { ratio }\end{array}$ \\
\hline $\begin{array}{l}\text { Control } \\
\text {. }\end{array}$ & $26.2^{\mathrm{ab}}$ & $1,109.5^{\mathrm{a}}$ & $156.7^{\mathrm{a}}$ & 7.65 & 28.9 & $679.9^{\mathrm{a}}$ & $119.8^{\mathrm{ab}}$ & 6.01 \\
\hline MOS & $25.0^{\mathrm{ab}}$ & $1,110.8^{\mathrm{a}}$ & $129.8^{\mathrm{ab}}$ & 8.87 & 32.5 & $693.7^{\mathrm{a}}$ & $136.3^{\mathrm{a}}$ & 5.47 \\
\hline FOS & $23.1^{\mathrm{b}}$ & $954.4^{\mathrm{b}}$ & $121.1^{\mathrm{b}}$ & 8.18 & 30.4 & $581.3^{\mathrm{b}}$ & $120.4^{\mathrm{ab}}$ & 5.12 \\
\hline Zn-bacitracin & $29.5^{\mathrm{a}}$ & $1,004.7^{\mathrm{ab}}$ & $128.3^{\mathrm{ab}}$ & 8.07 & 31.8 & $586.1^{\mathrm{b}}$ & $95.6^{\mathrm{b}}$ & 7.58 \\
\hline Pooled SE & 1.7 & 39.3 & 9.9 & 0.55 & 1.8 & 24.6 & 10.2 & 0.93 \\
\hline $\mathrm{p}$ value (diet) & 0.060 & 0.010 & 0.070 & 0.400 & 0.500 & 0.001 & 0.050 & 0.200 \\
\hline
\end{tabular}

${ }^{\mathrm{a}, \mathrm{b}}$ Means within a column with different superscripts are significantly different $(\mathrm{p}<0.05)$.

Nutrition can modulate the immune response of the bird by affecting the development of lymphoid organs, including the bursa and spleen, especially during the early age post hatch. Thus Wyatt et al. (1986) established that birds with delayed access to nutrients post hatch had impaired growth of lymphoid organs. In a recent study, Ao et al. (2012) demonstrated birds that had access to nutrients early in life had enhanced bursa and spleen growth. In addition, when MOS was supplemented in broiler diets immediately after hatch, it increased the production of IL-6. In the current study, the bursa and spleen weights were not affected by dietary supplementation. The birds used in this study were fed immediately after placement in clean cages and despite the effort to create a mild environmental challenge by adding used chicken manure on the floors of the cages, it did not appear to receive any disease challenge. Thus, the nutrition and environment for the birds were near optimal and there was probably no stress on the immune system. This begs the question whether lymphoid organ development and immunity of birds would respond differently to dietary supplements depending on the environmental conditions under which they are reared.

In this study, both FOS and MOS tended to increase cecal propionic acid concentration but none of the supplements had an effect on acetate, butyrate, total VFA concentrations, or on the $\mathrm{pH}$ of caecal contents. Short-chain fatty acids, especially butyric acid, from the fermentation of carbohydrates by gut microflora, are reported to reduce the $\mathrm{pH}$ of intestinal contents and had anti-bacterial properties (Meynell, 1963; Bohnhoff et al., 1964). Indeed, it is welldemonstrated that supplementation of oligosaccharides increase fermentation in the ceca, end products of which are predominately acetate, propionate and butyrate (Campbell et al., 1997; Jozefiak et al., 2004).

The diets used in this study were sorghum-soybean based and the NSP contents were relatively low. This might explain the higher cecal $\mathrm{pH}$ value and lower intestinal VFA concentrations as the microbial activity could be inhibited by improvement in digestibility and reduction of NSP content in the diet (Bedford, 2000).

The growth and development of GIT and digestive organs use a large proportion of nutrients the bird absorbs. It has been established that there is an interaction between the gut microflora and morphology of the GIT (Heneghan, 1965). MOS supplementation has been reported to increase villus height and reduce crypt depth in poultry (Savage et al., 1997; Baurboo et al., 2007). This indicates that the resistance to pathogenic bacterial invasion induced by MOS may be associated with measurable morphological changes of the intestinal mucosa.

In the current study, only Zn-bacitracin markedly increased the villus height and villus height/crypt depth ratio in the jejunum at $d$ 21. Interestingly, regardless receiving MOS, FOS or Zn-bacitracin, the birds had shorter ileal villi at $d 21$. It can be speculated that the microbial activity in the GIT was less vigorous, and hence the stressors on the defense mechanism of the birds.

Gordon and Bruckner-Kardoss (1961) reported in germfree animals that the villi are uniform, whereas crypts are shorter. Cook and Bird (1973) demonstrated that an increase in pathogenic bacteria in the GIT could result in shorter villi and deeper crypts. As a consequence, the absorptive area may be reduced and more proteins and energy are required for maintenance of the digestive tract (Hampson, 1986).

The current study showed that oligosaccharides, such as MOS and FOS, can improve growth performance and flock uniformity in broilers through positively affecting the morphological development of the GIT. This is an important finding for commercial poultry production, as finding a suitable and practicable alternative to in-feed antibiotics is essential for maintaining performance and profitability in many parts of the world, where in-feed antibiotics are banned or limited in their use in poultry diets.

\section{REFERENCES}

Ammerman, E., C. Quarles and P. V. Twinning, Jr. 1988. Broiler response to the addition of dietary fructooligosaccharides. Poult. Sci. 67:46(Abstr).

Ammerman, E., C. Quarles and P. V. Twinning, Jr. 1989. Evaluation of fructuoligosaccharides on performance and carcass yield of male broilers. Poult. Sci. 68:167(Abstr).

Apajalahti, J., A. Kettunen and H. Graham. 2004. Characterisation 
of the gastrointestinal microbial communities, with special reference to the chicken. World's Poult. Sci. J. 60:223-232.

Ao, Z., A. Kocher and M. Choct. 2012. Effects of dietary additives and early feeding on the performance, gut development and immune status of broiler chickens challenged with Clostridium perfringens. Asian-Aust. J. Anim. Sci. 25:541-551.

Bedford, M. R. 2000. Exogenous enzymes in monogastric nutrition - their current value and future benefits. Anim. Feed Sci. Technol. 86:1-13.

Bohnhoff, M., C. P. Miller and W. R. Martin. 1964. Resistance of the mouse's intestinal tract to experimental Salmonella infection. I. Factors which interfere with the initiation of infection by oral inoculation. J. Exp. Med. 120:805-816.

Baurhoo, B., P. R. Ferket and X. Zhao. 2009. Effects of diets containing different concentrations of mannanoligosaccharide or antibiotics on growth performance, intestinal development, cecal and litter microbial populations, and carcass parameters of broilers. Poult. Sci. 88:2262-2272.

Brown, R. H. 1996. The living gut must be considered when trying to eliminate pathogens. Feedstuffs 68:14.

Campbell, J. M., G. C. Fahey and B. W. Wolf. 1997. Selected indigestible oligosaccharides affect large bowel mass, cecal and fecal short-chain fatty acids, $\mathrm{pH}$ and microflora in rats. $\mathrm{J}$. Nutr. 127:130-136.

Cook, R. H. and F. H. Bird. 1973. Duodenal villus area and epithelial cellular migration in conventional and germ-free chicks. Poult. Sci. 52:2276-2280.

Duncan, D. B. 1955. Multiple range test and multiple F-tests. Biometrics 11:1-42.

Gordon, H. A. and E. Bruckner-Kardoss. 1961. Effect of normal microbial flora on intestinal surface area. Am. J. Physiol. 201: 175-178.
Hampson, D. J. 1986. Alterations in piglet small intestinal structure at weaning. Res. Vet. Sci. 40:32-40.

Heneghan, J. B. 1965. Imbalance of the normal microbial flora: The germfree alimentary tract. Am. J. Dig. Dis. 10:864-869.

Jozefiak, D., A. Rutkowski and S. A. Martin. 2004. Carbohydrate fermentation in the avian ceca: a review. Anim. Feed Sci. Technol. 113:1-15

Klasing, K. C. 2007. Nutrition and the immune system. Br. Poult. Sci. 48:525-537.

Kumprecht, I., P. Zobac, V. Siske and A. E. Sefton. 1997. Effects of dietary mannanoligosaccharide level on liveweight and feed efficiency of broilers. Poult. Sci. 76:132.

Lloyd, A. B., R. B. Cummings and R. D. Kent. 1977. Prevention of Salmonella typhimurium infection in poultry by pretreatment of chicks and poults with intestinal extracts. Aust. Vet. J. 53:82-87.

Meynell, G. G. 1963. Antibacterial mechanisms of the mouse gut. II. The role of $\mathrm{pH}$ and volatile fatty acids in the normal gut. $\mathrm{Br}$. J. Exp. Pathol. 44:209-219.

Savage, T. F., E. I. Zakrzewska and J. R. J Andreasen. 1997. The effects of feeding mannan oligosaccharide supplemented diets to poults on performance and the morphology of the small intestine. Poult. Sci. 76(Suppl. 1):139.

Sims, M. D., M. F. White, T. W. Alexander, T. Sefton, A. Connolly and P. Spring. 1999. Evaluation of Bio-Mos fed alone and in combination with BMD to growing Tom turkeys. Poult. Sci. 78:105 (Abstr).

Wyatt, C. L., J. Weaver, W. D. Beane, W. L. Denbow and W. B. Gross. 1986. Influence of hatcher holding times on several physiological parameters associated with the immune system of chickens. Poult. Sci. 65:2156-2164. 